\title{
Seed systems smallholder farmers use
}

\author{
Shawn McGuire ${ }^{1} \cdot$ Louise Sperling $^{2}$
}

Received: 22 September 2015 / Accepted: 16 November 2015 /Published online: 18 January 2016

(C) The Author(s) 2015. This article is published with open access at Springerlink.com

\begin{abstract}
Seed can be an important entry point for promoting productivity, nutrition and resilience among smallholder farmers. While investments have primarily focused on strengthening the formal sector, this article documents the degree to which the informal sector remains the core for seed acquisition, especially in Africa. Conclusions drawn from a uniquely comprehensive data set, 9660 observations across six countries and covering 40 crops, show that farmers access $90.2 \%$ of their seed from informal systems with $50.9 \%$ of that deriving from local markets. Further, $55 \%$ of seed is paid for by cash, indicating that smallholders are already making important investments in this arena. Targeted interventions are proposed for rendering formal and informal seed sector more smallholder-responsive and for scaling up positive impacts.
\end{abstract}

Keywords Informal and formal seed sectors - Agricultural investment $\cdot$ Markets $\cdot$ Smallholder $\cdot$ Delivery $\cdot$ Access to seed

\section{Introduction}

Seed sector development specifically geared to smallholder farmers has attracted substantial investment in recent years.

The writers share first authorship.

Shawn McGuire

s.mcguire@uea.ac.uk

Louise Sperling

louise.sperling@crs.org

1 School of International Development, University of East Anglia, Norwich NR4 7TJ, UK

2 Catholic Relief Services, 228 West Lexington Street, Baltimore, MD 21201, USA
As examples, from 2007 to 2012, the World Bank funded 87 seed sector projects, worth \$ US 513 million, with a strong focus on the vulnerable (Rajalahti 2013) and, in the same period, the Alliance for a Green Revolution in Africa's Program for Africa's Seed Systems (AGRA/PASS) dispensed 112 grants totaling $\$ 35,244,164$ and geared to improving smallholder livelihoods (SourceWatch 2012).

The broad rationale for focusing on seed sector interventions is that seed is a vehicle for delivering a range of advances, all of which can benefit smallholders. Seed can be the conduit for moving new varieties, giving farmers access to more productive, yield-enhancing traits. New seed is linked to strategies for raising nutrition, as with biofortified varieties selected for elevated micro-nutrient levels (Bouis and Welch 2010). Further, in response to climate variation, stress-tolerant varieties or clusters of diverse varieties are promoted as 'good practice' to enhance system resilience: multiple options can allow farmers to shift crop or variety portfolios in response to changing conditions (McGuire and Sperling 2013). Hence, seed is a vehicle linked to promoting productivity, nutrition and resilience: one entry point can potentially move forward multiple goals.

Varied and often opposing philosophies shape seed sector development and much depends on what actors see as the starting point for system entry. Organizations such as AGRA/PASS invest their resources mainly in private sector seed business development, that is, in the promotion of private commercial seed and formal sector input companies. In contrast, select nongovernmental organizations (NGOs) and donors have signaled the need to support more locally-driven initiatives and particularly those that organize around what are called informal, farmer-based, local or traditional 
seed sector operations (e.g., GTZ 2000). ${ }^{1}$ Activities here tend to be decentralized and might revolve around local entrepreneurship, seed banking, community-based seed production, or seed villages. While proponents of formal or informal seed sector development seem divided and even polarized in their respective zones of influence, farmers, in practice, often engage in actions to smooth the divides. For instance, on the demand side, farmers have long drawn from both formal and informal systems, accessing seed for different crops from distinct channels, e.g., maize from agro-dealers and groundnuts from local markets (Sperling and Cooper 2004). On the supply side, an increasing number of farmers are involved in participatory variety selection, sit on variety release committees, or access improved varieties through local trader networks (Sperling et al. 2014). More recently, initiatives to recognize and explicitly plan for an 'integrated seed sector' have started to be sketched (Almekinders and Hardon 2000; Louwaars and de Boef 2012; Sperling et al. 2014), but pivotal points for catalyzing formal and informal integration tend to be ad hoc rather than managed, and are localized, rather than achieved at scale (Sperling et al. 2014). The Bill and Melinda Gates Foundation (BMGF), in particular, is aiming to become a champion in this area labeled "Integrated Seed Sector Development" (Louwaars et al. 2013).

Worldwide, recent figures on the seed market valuation estimate the commercial worth of these seed sectors, with the formal sector being valued at \$US 45 billion annually and the informal sector at between \$US 6 and 15 billion annually (Bonny 2014). ${ }^{2}$ However, the figures are somewhat misleading in isolation. Reflecting on geography, in the South, the commercial and informal sector sizes might be more equitable, even in money terms. Also, the focus on commercial worth does not necessarily correlate with the value of each system to end-users: discussion narrows towards immediate financial gain and away from real impacts in farmers' fields. Finally, brute figures disguise exactly who is served by these varied seed system domains.

If seed sector development is to be geared specifically to smallholder agricultural development (practically, not just nominally), strategic insights into how farmers actually use varied seed channels might drive the seed sector development process more centrally. Empirically, where do farmers get the planting materials they sow, season after season, for which crops, where, on what scale? Multiple descriptions of seed system use do exist in the refereed and particularly grey literature - especially from anthropologists and agricultural economists (Badstue 2006; McGuire 2008; Nagarajan et al.

\footnotetext{
${ }^{1}$ Each of these terms has a particular nuance, and each is problematic. 'Informal' systems are not purely 'farmer' systems in that markets are important. Neither are they purely 'local' since both markets and exchange through social networks connect various localities. Finally, they are not 'traditional' in the strict sense, because they are constantly evolving.

${ }^{2}$ Unfortunately, no figures presently have been put forward for the integrated seed system interface.
}

2007). Existing studies tend to be of two types ${ }^{3}$ : those that focus on intensive single crop analyses and often at a single site (e.g., Christinck 2002) or relatively sweeping regional and national analyses, which look at broad household socio-economic parameters and give insight on what might be happening in select seed-related domains (e.g., Nordhagen and Pascual 2013).

This article focuses on the empirical. It is rooted in what the authors believe is the largest specialized seed system dataset in the world, some 9660 observations and growing. Analyses indicate where smallholder farmers obtain seed for their most important crops (some 40 across sites), crop by crop, under what conditions (e.g., bought, loaned, exchanged) and how varied trade-offs shape the use of some nine different seed channels. The work does not claim to be representative of global trends, as five of the six cases are based in Africa, with the sixth in Haiti. However, the breadth of data is such that the article raises questions about support strategies for achieving seed system gains at scale, on a sustained basis, and that serve the smallholder farmer. It is this type of aggregated seed-specific research and analysis, focused on smallholders, that might be used to inform where catalytic seed sector investments should be made.

\section{Methods}

\section{The SSSA: overview}

The data presented in this article were collected in the course of conducting seed system security assessments (SSSAs). Such SSSAs are a relatively new method of analysis (Byrne et al. 2013; Sperling 2008) and examine the functioning of all the seed systems farmers use. These include the 'formal channels' that give farmers access to modern varieties and certified seed (from the government, commercial seed companies, sometimes relief providers); and 'informal channels' (from farmers' own harvests, social networks, or local markets) that provide farmers with a range of varieties (modern, new local, local) and seed (or 'potential seed') of varying quality. ${ }^{4}$ In addition, the data encompass more occasional, interstitial conduits, for example, seed from community-based seed production groups (CBSGs).

SSSAs have a strong focus on smallholder farmers. SSSAs are most often conducted in zones where seed sector interventions are being considered to bolster smallholder agriculture: through rural development or agro-enterprise initiatives, safety net programs or short-term assistance. As such, these

\footnotetext{
${ }^{3}$ We recognize that there are hundreds of seed system cases studies, some of which cannot be easily characterized within this dichotomy. Here, we signal what seem to be the main trends.

${ }^{4}$ Not all grain found in informal channels can be used as seed. However, there is a subset of material that is adapted and carefully managed, which farmers save or seek specifically for planting. The authors term this material as 'potential seed' or 'implicit seed' (Sperling and McGuire 2010).
} 
assessments review seed security issues for smallholder farmers engaged in market-oriented farming, for those more subsistence oriented, for those in chronic stress situations, and, occasionally, for populations marked by an acute stress, such as an earthquake, or prolonged drought. While SSSAs do not explicitly highlight commercial farming areas, these zones are sometimes included within national-scale assessments that aim to cover a broad range of agro-ecological and geographic regions.

\section{Sites}

Data from six distinct assessments are presented in this article. All SSSAs were conducted between 2009 and 2012. Table 1 lists the assessment sites along with salient descriptors of their contexts. Both South Sudan and Haiti were countrywide assessments and covered a large set of agro-ecological zones and crops. The others were more region-specific, although even these focused samples embraced multiple sites and farming systems. ${ }^{5}$ The Zimbabwean assessment included four distinct agro-ecological zones: the Kenyan one focused on droughtprone regions in the east and coastal areas; the Democratic Republic of Congo (DRC) assessment was centered in northern Katanga, and the Malawi SSSA extended across the southern zone. Mapping and extensive characterization of individual assessment sites appear in each respective SSSA report (http://seedsystem.org/field-assessments-action-plans/) and the reference list provides the individual case study links.

Most assessment sites broadly exhibited features linked with rural smallholder agriculture: e.g., poor infrastructure development, erratic access to agriculture development efforts, little value addition in terms of agro-processing. Further, three SSSAs took place immediately during or after key events potentially affecting farming systems. The Zimbabwe SSSA was carried out mid 2009, shortly after a period of hyperinflation which rendered the local currency virtually worthless (Hanke and Kwok 2009). The South Sudan assessment unfolded in the months just prior to the 2011 Referendum as the country transitioned toward an independent state, and the Haiti assessment was conducted several months post-earthquake 2010. However, while the effects of these immediate stresses were noted, in all cases it was chronic stress factors that largely shaped the seed security scenarios. For instance, in the case of Haiti, over $90 \%$ of the assessment sites fell outside of the areas of direct earthquake impact (i.e., including eastern and northern areas which had very little displaced population overflow); in South Sudan, only c. $50 \mathrm{~km}$ of macadam were paved countrywide both immediately before and after the Referendum Period.

\footnotetext{
${ }^{5}$ The South Sudan Assessment took place just pre-referendum, in October and November 2010. Officially the region was then known as southern Sudan as this southern region was not yet a country in its own right.
}

It is notable that the profile of sites broadly evokes the type of areas in which significant seed system investments and seed aid interventions are routinely proposed, ranging at varied points from agro-enterprise, development, recovery and select relief programs (Table 1).

\section{Partners and sample}

Across sites, upwards of 25 organizations were involved in the SSSAs, ${ }^{6}$ including government institutions (agricultural ministries and seed services), the United Nations (UN), national agricultural research systems, national universities, nongovernmental organizations (NGOs), faith-based groups, and farmers' cooperatives and farmer unions. Each SSSA engaged at least five different organizations on the ground, helping to counteract potential single institutional bias.

Site selection within SSSAs was geared towards general zones where government, UN or NGO interventions were being implemented. While some collaborating organizations chose zones where explicit agricultural programs were unfolding, in other cases, health or literacy campaigns were the primary programs being unrolled. The site selection suggested populations with relatively good access to developmental, safety net or short-term aid.

In each site, on average 84 households were interviewed. Systematic random sampling was employed (Levy and Lemeshow 2008), interviewing every third or fourth household depending on population density. In total, data were collected for 2592 households.

\section{Field instruments}

Standardized instruments were used across sites (see samples posted at http://seedsystem.org). Beyond the quantitative household surveys reported herein, instruments were tailored towards understanding the actions of key actor groups, inter alia: government personnel, farming communities, private sector seed companies and agro-dealers, women's groups, seed/grain market traders, agricultural product processors, and humanitarian and development groups. Further, the field instruments aimed for a high level of differentiation in seed security investigation. As one example, instruments distinguished nine possible seed sources: farmers' own stores or fields ('own stock'); kin, neighbors, or friends (social networks); local markets $^{7}$; agro-dealers or agro-vets; community-based seed groups

\footnotetext{
${ }^{6}$ This number of organizations is an underestimate. In some cases, professionals participated in assessments as individuals, usually to learn the SSSA methodology, rather than officially representing their organizations. Such individual participation is not tallied in the total.

7 'Local markets' generally refer to the open air venue where farmers get agricultural and other goods. Small kiosks surrounding these open areas are also included in the term (see Sperling and McGuire 2010 for greater clarification).
} 
Table 1 Select site descriptors for seed system security assessments (SSSAs), with sample sizes for number of households interviewed (HH) and number of individual seed access transactions noted (transaction: HH x crop x source)

\begin{tabular}{|c|c|c|c|c|c|}
\hline \multirow[t]{2}{*}{ SSSA Country (Region) } & \multirow[t]{2}{*}{ Date } & \multicolumn{2}{|l|}{ Stress context } & \multirow{2}{*}{$\begin{array}{l}\mathrm{N} \\
\mathrm{HH}\end{array}$} & \multirow[t]{2}{*}{ Transaction } \\
\hline & & Ongoing (chronic) stresses & Immediate events & & \\
\hline Malawi (Southern) & 2011 & Low purchasing power Repeated droughts & - & 180 & 682 \\
\hline Kenya (East and Coast) & 2011 & Decline of maize, low purchasing power Repeated droughts & - & 198 & 745 \\
\hline DR Congo (Katanga) & 2012 & Low innovation, weak infrastructure Ongoing conflict & - & 209 & 548 \\
\hline Haiti & 2010 & Weak state, low innovation & Earthquake (corner of country) & 983 & 3056 \\
\hline South Sudan & 2010 & Weak state \& infrastructure & Pre-Referendum 'fear' & 857 & 4017 \\
\hline Zimbabwe & 2009 & Declining purchasing power & Hyper currency inflation & 165 & 612 \\
\hline TOTAL & & & & 2592 & 9660 \\
\hline
\end{tabular}

(CBSG); some form of assistance : government ('government') or non-government or United Nations ('NGO/UN'); contract growers (who are side-selling); or 'other'.

All instruments were translated to the main national languages, with key terms further translated into local languages. For instance, in the South Sudan SSSA, terms such as modern variety, local variety, certified seed, local seed, and hybrid were translated into 10 local languages (plus English) to accommodate ethnic variations across the country.

\section{Data set: scope and analysis}

Data collection was followed intensively: the authors and other seed system specialists directly trained enumerators, reviewed forms while in the field, and monitored coding and data-entry at each site. Multiple stages of data-cleaning were effected including via verification algorithms. A programming tool allowed real-time synthesis by automating data analysis: following data-entry in Excel, descriptive statistic tables were immediately generated even for large data sets of $900+$ cases. Such rapid turnaround allowed field teams to garner (and validate) quantitative findings and shape follow-up probing, e.g., why farmers were planting more or less than usual. Combined datasets were analyzed with SPSS (version 22) and STATA (version 11) for Probit regressions.

Given this range of processes- standardized tools across sites; cleaning and cross-checking in the field; automated analysis (eliminating some bias or user error); and follow-up of outliers on site- the authors sense this dataset not only to be the largest currently available, but among the more rigorous. Certainly it is among the larger sets using a suite of standardized, seed system-specific instruments.

\section{Results}

Results are organized below along four farmer-centered questions; which seed channels were used overall, and for select crops; how seed was acquired; who used specific channels; and focusing on the varietal aspects of seed, how farmers accessed new varieties. The questions broadly cover parameters central to understanding seed security: seed availability, accessibility and quality (McGuire and Sperling 2011; Remington et al. 2002).

\section{Which seed channels did farmers use?}

\section{Across crops}

Farmers detailed all the sources used to obtain seed, with their exact amounts, for their three major crops during the most recent season tied to the assessment. ${ }^{8}$ Table 2 presents the volumes provided by each source, across all crops. Several findings are of note: overall, slightly over half of all seed (50.9\% across crops), was obtained from the local market, indicating that this source, quantitatively, was the most important of the $9+$ sources monitored. ${ }^{9}$ The local market was also the dominant seed source in four out of the six SSSAs: Haiti, Kenya, Malawi and DRC. For the two exceptions, market access was constrained during the assessment periods: Zimbabwe was facing a currency breakdown and localized bartering of goods often substituted for cash payment. In South Sudan, lack of road infrastructure made market use a second, rather than primary seed source, albeit still an important one. The extreme use of local markets in Haiti, almost $3 / 4$

\footnotetext{
${ }^{8}$ In each site, standard conversion rates from local units of measure to $\mathrm{kg}$ were agreed with collaborating partners to get at the issue of volumes of seed from each source. Often, these were well-established conversion rates for local measures in common usage. Units for vegetativelypropagated crops such as cassava were converted to propagules (cuttings, pseudostems, etc.); to make these comparable with seed crops, quantities of propagules were converted to $\mathrm{kg}$ equivalent figures by relating the recommended sowing rate for a vegetative crop with a standard sowing rate for maize. For instance, common sowing rates for cassava and maize are 10000 stems and $25 \mathrm{~kg}$, respectively, so 400 cassava cuttings were converted to $1 \mathrm{~kg}$ for comparative purposes.

${ }^{9}$ For this, and other tables, figures for 'All Sites' represent proportions of total seed volumes across all six sites.
} 
Table 2 The sources supplying seed in most recent season, as a \% of total seed supplied in each SSSA site

\begin{tabular}{|c|c|c|c|c|c|c|c|}
\hline \multirow[t]{2}{*}{ Seed source } & \multicolumn{6}{|c|}{ SSSA country $(\%)$} & \multirow[t]{2}{*}{ All sites } \\
\hline & Malawi & Kenya & DRC/Katanga & Haiti & S Sudan & Zimbabwe & \\
\hline Own Stock & 28.3 & 36.2 & 35.0 & 17.4 & 42.2 & 45.2 & 31.1 \\
\hline Friend, neighbor, relative & 7.8 & 5.7 & 16.9 & 3.3 & 12.1 & 21.9 & 8.6 \\
\hline Local market & 32.0 & 40.1 & 44.6 & 73.0 & 34.3 & 9.9 & 50.9 \\
\hline Agro-dealer & 17.5 & 11.6 & 0.4 & 1.5 & 0.2 & 5.8 & 2.4 \\
\hline CBSG & 0.1 & 0.0 & 0.1 & 0.8 & 0.2 & 0.3 & 0.5 \\
\hline Government & 8.9 & 5.1 & 0.0 & 0.4 & 0.6 & 11.5 & 1.6 \\
\hline $\mathrm{NGO} / \mathrm{UN}$ & 4.2 & 0.9 & 3.1 & 3.3 & 10.4 & 4.8 & 5.7 \\
\hline Contract growers & 0.5 & 0.1 & 0.0 & 0.0 & 0.0 & 0.5 & 0.1 \\
\hline Other & 0.7 & 0.3 & 0.0 & 0.2 & 0.0 & 0.0 & 0.1 \\
\hline Total \% & 100.0 & 100.0 & 100.0 & 100.0 & 100.0 & 100.0 & 100.0 \\
\hline Total $\mathrm{kg}^{\mathrm{a}}$ & 4529.1 & 5266.8 & 7688.9 & 42842.2 & 33536.1 & 4789.2 & 98652.3 \\
\hline
\end{tabular}

CBSG Community-based seed group; NGO Non-governmental organization; UN United Nations (often the Food and Agriculture Organization)

${ }^{a}$ For vegetatively-propagated crops such as cassava, propagule quantities were converted to kg equivalents. See note 8

of all seed sown, may be the highest recorded in the seed system literature anywhere. This means that Haitian farmers are turning over the majority of seed stocks season after season, in what can be a variable supply system.

Own stocks were also important, providing $1 / 3$ of seed sown overall, varying between 28 and $45 \%$ in all sites, with the exception of Haiti. The secondary rather than primary importance of use of own stocks challenges several common stereotypes: first, the notion that smallholder farmers will prioritize seed saving in times of stress (De Waal 1991) and, second, that own-saved seed provides the bulk of smallholder sowings (e.g., Bezner Kerr 2013; Cavatassi et al. 2011; Guei et al. 2011; Marfo et al. 2008). Simply, overall data show that the locus of seed sources is off-farm, not within farm.

Use of sources beyond markets and own stocks was modest. Seed from social networks supplied under $1 / 10$ of total seed sown. Agro-dealers, that is, the private input company networks which put on offer modern varieties and certified seed, proved to be an insignificant source of seed for smallholder farmers, across crops and sites, supplying $2.4 \%$ of seed used. Key to emphasize is that for over 2500 farmers spread across 31 sites in six countries, seed sources utilized were few in number and overwhelmingly dominated by two: local markets and own stocks.

\section{Within crop clusters}

Table 3 draws from the same data set, but from a crop perspective. Crops have been grouped into common clusters of cereals, legumes, and vegetatively-propagated crops (VPCs) to highlight trends by crop type. Maize was kept as a separate category given its importance across much of Africa and its prominence in seed sector development (Shi and Tao 2014).
The category 'Other' groups 17 mostly horticultural crops, generally sown in small quantities.

Table 3 shows that the relative importance of seed sources varies markedly by crop cluster. Local markets are the driving seed source for legumes, providing almost $2 / 3$ of the seed sown. For all major legumes, markets supplied from 49.5 to $81.3 \%$ of all crop-specific seed sown (with the ranges indicating greengram and common bean market use, respectively).

Own stocks are especially central for the VPCs (e.g., providing nearly $80 \%$ of sweet potatoes cuttings) as well as for dryland cereals (sorghum and millets). For these latter crops, small seeds and dry storage conditions present fewer challenges to self-storage than for legumes such as beans (Sperling and McGuire 2010). Use of social networks was noted in greatest quantity for the VPCs, partly as the market option here is so limited.

As agro-dealer use overall was very modest, this channel is better understood through examining use by specific crop. The source has some importance for maize (see also Fig. 1 below), and for highly commercialized crops in specialized production contexts such as rice in the Artibonite region of the Haiti, ${ }^{10}$ or subsidized contract farming of cotton in Malawi. If cotton were removed from the 'other' crop category, agro-dealer use falls to $2.1 \%$ for this cluster. Of note, is the near absence of agro-dealer use as a seed source for the full clusters of legumes and VPC crops, that is $<1 \%$ of the total seed sourced. This is an important gap area for clusters of crop types key for basic nutrition and calorie provision.

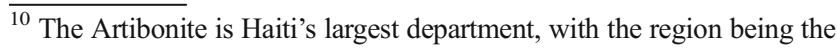
country's main rice-growing area. (http://en.wikipedia.org/wiki/ Artibonite_Department)
} 
Table 3 Source of seed for most recent season, by crop cluster, across all sites

\begin{tabular}{|c|c|c|c|c|c|c|c|c|c|c|}
\hline \multirow[t]{2}{*}{ Crop } & \multicolumn{9}{|c|}{ Seed source: 'most recent/current season' (\%) } & \multirow[t]{2}{*}{ Total - All sources $(\mathrm{kg})$} \\
\hline & $\begin{array}{l}\text { Own } \\
\text { stock }\end{array}$ & $\begin{array}{l}\text { Friend, } \\
\text { neighbor, } \\
\text { relative }\end{array}$ & Local market & Agro-dealer & CBSG & Government & $\mathrm{NGO} / \mathrm{UN}$ & $\begin{array}{l}\text { Contract } \\
\text { growers }\end{array}$ & Other & \\
\hline Maize & 30.3 & 9.5 & 41.9 & 6.1 & 0.2 & 4.8 & 6.4 & 0.1 & 0.0 & 22893.8 \\
\hline Other cereals & 40.0 & 12.1 & 37.9 & 2.2 & 0.8 & 0.9 & 6.0 & 0.0 & 0.0 & 15995.1 \\
\hline Sorghum & 51.2 & 12.1 & 28.3 & 0.2 & 0.1 & 1.1 & 7.1 & 0.1 & 0.0 & 9835.7 \\
\hline Millets & 44.6 & 21.1 & 18.7 & 0.7 & 0.0 & 2.4 & 12.4 & 0.0 & 0.1 & 1469.6 \\
\hline Rice & 15.1 & 9.3 & 64.3 & 6.9 & 2.5 & 0.0 & 1.9 & 0.0 & 0.1 & 4689.8 \\
\hline Legumes $^{\mathrm{a}}$ & 24.2 & 4.0 & 64.4 & 0.6 & 0.5 & 0.6 & 5.5 & 0.0 & 0.2 & 50670.1 \\
\hline Groundnut & 34.8 & 6.4 & 51.7 & 0.1 & 0.3 & 0.2 & 6.6 & 0.0 & 0.1 & 23994.3 \\
\hline Common bean & 10.4 & 0.9 & 81.3 & 0.8 & 0.9 & 0.4 & 5.1 & 0.0 & 0.2 & 20778.8 \\
\hline Cowpea & 26.7 & 4.4 & 56.6 & 2.4 & 0.5 & 4.4 & 5.0 & 0.0 & 0.0 & 1937.6 \\
\hline Pigeonpea & 30.1 & 5.5 & 61.4 & 0.4 & 0.2 & 1.4 & 0.6 & 0.0 & 0.3 & 2010.2 \\
\hline Green gram & 37.1 & 2.2 & 49.5 & 2.9 & 0.0 & 4.6 & 1.6 & 0.0 & 0.5 & 1597.5 \\
\hline VPCs & 47.3 & 29.9 & 18.3 & 0.1 & 0.5 & 0.4 & 3.2 & 0.0 & 0.4 & 7441.8 \\
\hline Cassava & 52.9 & 32.4 & 9.5 & 0.0 & 0.3 & 0.5 & 4.3 & 0.0 & 0.1 & 4951.3 \\
\hline Banana & 16.0 & 26.0 & 54.7 & 0.4 & 0.8 & 0.0 & 0.6 & 0.0 & 1.6 & 1407.9 \\
\hline Sweet potato & 79.2 & 14.6 & 3.5 & 0.0 & 0.0 & 0.0 & 2.7 & 0.0 & 0.0 & 609.7 \\
\hline Irish potato & 38.8 & 36.7 & 22.0 & 0.0 & 2.0 & 0.0 & 0.1 & 0.0 & 0.4 & 432.8 \\
\hline Others $^{\S}$ & 22.9 & 9.1 & 33.5 & 22.3 & 0.0 & 1.4 & 8.7 & 1.5 & 0.7 & 1641.5 \\
\hline
\end{tabular}

${ }^{a}$ More minor legumes and VPCs are not displayed, but are included in totals. For the legumes: chickpea, Bambara nut, velvet bean, lima bean For the VPCs: yams and taro

$\S$ 'Others' include 17 crops, mostly horticultural crops sowed in small quantities, with a few in more appreciable amounts: sesame, cotton, okra, pumpkin

\section{Maize}

Maize seed is given separate focus as this crop is an engine for public and private seed sector investment, at least in much of Africa (Langyintuo et al. 2010). To home in on possible commercial trends in farmers' sourcing of

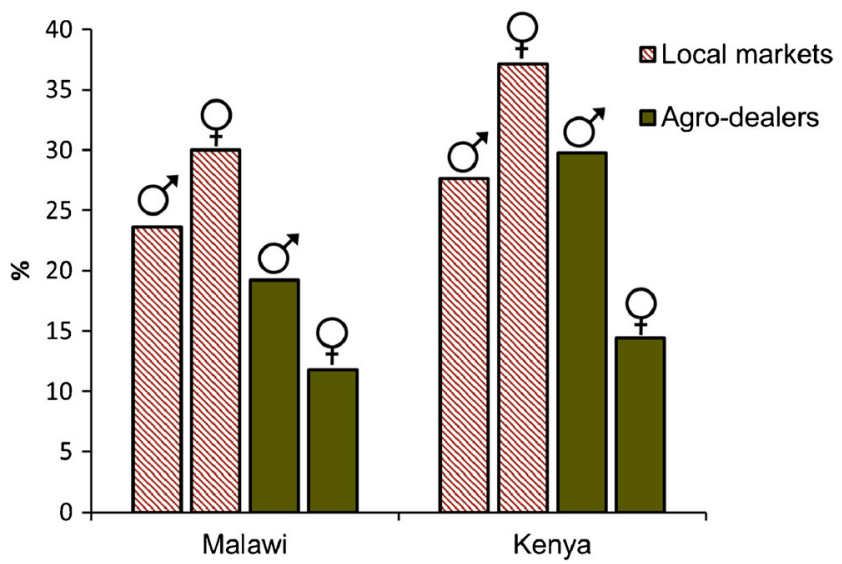

Fig. 1 Market seed sources for maize as \% of all seed supplied for maize in Malawi and Kenya, disaggregated by gender; $\hat{\partial}=$ male-headed households $(n=186$ for Malawi, 117 for Kenya), $9=$ female-headed households ( $n=107$ for Malawi, 54 for Kenya), total $n=464$ maize seed, analysis was explicitly narrowed to countries within the data set where: a) maize is the most important crop, as measured in hectares sown (Smale et al. 2011) and where: b) agro-dealer networks are relatively more developed (Chisinga 2011; Odame and Muange 2011). Kenya and Malawi clearly stand out here in comparison to eastern DRC, South Sudan, and Haiti. While Zimbabwe is both maize-centered and with a formidable commercial input sector (especially when linked to cross-border South African private company supply), input trade was near halted at the time of the SSSA, at least for legal formal transactions.

Figure 1 shows the proportions of maize seed sourced from local markets and agro-dealers for these two countries. Both types of markets are important seed sources, each providing $17-31 \%$ of maize seed sown by smallholders. However, local markets supply relatively more maize seed than agro-dealers, even for this highly commercialized crop. Further, gender disaggregation shows a more pronounced trend towards local markets for female-headed households. Female-headed households seem to steer their seed purchases towards the markets where they can also buy other household supplies, e.g., salt and soap, and an array food goods, such as chili peppers, greens and fish. 


\section{Crop diversity}

In terms of channels, the final issue addressed is the diversity of crops accessed by farmers from the varied conduits. Some 40 crops were monitored in the data set, with most crops found across multiple SSSA sites.

Agro-dealer networks supplied appreciable quantities only for maize and rice (the latter mostly in Haiti), and marked proportions (i.e., at least $5 \%$ ) of only three other crops, all in Malawi: pumpkin (27\% from agro-dealers); mustard leaves $(15.6 \%)$ and cotton $(76.4 \%)$. Cotton is the only crop within the entire SSSA sample where dealer supply exceeded local market supply: it is a unique case where specific commercial enterprises provided seed to outgrowers. Legume seed, in contrast, was only very occasionally sourced from agrodealers: cowpea and greengram reached levels of 2.4 and $2.9 \%$ of total seed sown respectively for each crop. Common bean, groundnut and pigeonpea fell below $1 \%$ of supply from agro-dealer networks.

Local markets supplied at least $5 \%$ of seed for 26 out of the 40 crops monitored, and over $10 \%$ of seed for 24 of these crops. While the total percentages vary considerably by crop, an important point is that local markets are routinely used for seed for a wide range of crops.

In sum, from an array of at least nine possible provision channels, only two presently supply important quantities of seed to smallholder farmers: local markets and farmers' own stocks. Markets additionally stand out in terms of their importance for accessing legume seed. Leveraging such markets could be key for helping farmers enhance family nutrition and improve soil fertility, two functions often associated with enhanced use of legumes (Giller 2001).

Markets might also warrant greater attention due to the diversity of seed and planting material they put on offer. Having access to a range of planting options is a central feature for encouraging current farming system resilience and for responding to the future climate-change spurred variations (McGuire and Sperling 2013).

\section{How seed was acquired}

The analysis now moves to looking at the ways farmers might access seed. Farmers might pay: through cash, exchange with other seed, or render casual labor for seed (which was a common arrangement in Malawi and Zimbabwe); receive gifts; take seed loans or money loans; and obtain seed through developmental or emergency seed programs. In select instances, food aid also may be planted, especially when maize and beans are given in grain form rather than ground or powdered. Note that seed even from the same channel can be accessed in different ways; for instance neighbors may give seed for free, or seek cash, among other mechanisms.
Understanding mechanisms is key for several reasons. Looking through a lens of vulnerability, one might want to know the degree to which farmers give seed freely to one another, especially to help poorer members of the community. Focusing on commercialization, one might ask whether farmers are willing to pay for seed and planting material, even when obtained from a neighbor.

\section{Relative importance of accessing mechanisms}

Table 4 summarizes how farmers in the SSSA samples actually accessed their seed. Almost $55 \%$ of all seed was paid for in cash, being bought from local markets, agro-dealers and even from social networks (for instance, cassava stems being purchased from neighbors while the crop was still in the field). While some of these purchases were from the formal sector outlets, a large portion also emerged from informal sector transactions (also see Table 5).

Table 4 also tracks other mechanisms for accessing seed. In term of quantities, only very small portions were obtained through exchange or seed or money credit, and gifts occupy less than $7 \%$ of the total seed accessed. All of these seeming 'neighborly' functions are key to monitor, as it is through such farmer-to-farmer inter-relationships that new varieties have often been posited to move (Aw-Hassan et al. 2008; Jones et al. 2001).

To double-check on such trends, another way of analyzing access mechanisms was used, the frequency of transactions (versus amounts, reported above). Transaction frequencies may give different insights, particularly when only small amounts are moved, such as a 'handful' of seed given neighbor to neighbor. The transaction frequency set of measures gives results comparable to the seed quantity measures: purchase is still overwhelmingly dominant amounting to $45 \%$ of all transactions, and exchange mechanisms remain very seldom used, only in $1.3 \%$ of cases. The main difference appears when analyzing gifts. Using frequency as the access tracking measure, gift transactions rose to $12.4 \%$ of all transactions involving seed access (Sperling et al. 2014).

All in all, the access mechanism data reveal a series of insights. First, farmers buy the majority of their seed. They already are 'willing to pay' (an issue pursued in the next section). Second, a focus only on dedicated markets, that is, on agro-dealers or open local markets, ignores an important segment of purchases in the countryside, directly from farmers' homes and fields. Several observations bear emphasis here. The seed systems farmers use are already highly market-driven. Also, tied to these cash layouts, there may be a large informal market that has yet to be exploited in terms of serving a potential customer base (Sperling et al. 2014).

The social network results also were somewhat surprising. Seed exchange among smallholder farmers seems not to be a major process in terms of seed quantities obtained or even 
Table 4 Means of access for all seed farmers sowed in most recent season $(\%$ of quantity sowed)

\begin{tabular}{|c|c|c|c|c|c|c|c|c|}
\hline \multirow[t]{2}{*}{ How obtained seed } & \multicolumn{6}{|c|}{ SSSA Site (\%) } & \multicolumn{2}{|c|}{ All sites } \\
\hline & Malawi & Kenya & DRC & Haiti & S Sudan & Zimbabwe & $\%$ & $\mathrm{Kg}$ \\
\hline Own stock & 28.3 & 36.1 & 34.7 & 17.3 & 42.2 & 45.2 & 30.0 & 29591.8 \\
\hline Exchange & 0.4 & 0.2 & 1.2 & 0.8 & 0.3 & 4.1 & 0.8 & 752.2 \\
\hline Gift & 1.8 & 3.3 & 10.9 & 2.1 & 11.4 & 16.0 & 6.7 & 6580.6 \\
\hline Buy $^{a}$ & 49.4 & 53.9 & 50.1 & 76.4 & 34.2 & 16.6 & 54.6 & 53893.4 \\
\hline Vouchers & 9.9 & 0.4 & 1.7 & 0.0 & 0.0 & 0.6 & 0.6 & 638.1 \\
\hline $\mathrm{DSD}^{\S}$ & 0.7 & 4.0 & 1.3 & 3.0 & 10.7 & 14.6 & 6.0 & 5910.7 \\
\hline Seed loan & 3.8 & 2.0 & 0.1 & 0.0 & 0.5 & 0.0 & 0.4 & 443.5 \\
\hline Food aid & 0.0 & 0.1 & 0.0 & 0.0 & 0.1 & 1.1 & 0.1 & 121.2 \\
\hline Money credit & 0.2 & 0.0 & 0.0 & 0.2 & 0.4 & 0.0 & 0.2 & 206.5 \\
\hline Other & 0.7 & 0.0 & 0.0 & 0.2 & 0.1 & 0.0 & 0.2 & 172.9 \\
\hline Casual labor & 4.9 & 0.0 & 0.0 & 0.0 & 0.0 & 1.8 & 0.3 & 307.7 \\
\hline TOTAL & 100.0 & 100.0 & 100.0 & 100.0 & 100.0 & 100.0 & 100.0 & 98618.6 \\
\hline
\end{tabular}

${ }^{a}$ Lower purchase figures in Zimbabwe and South Sudan, reflect the same patterns described relating to constrained market functioning: currency breakdown and poorly developed roads allowing access to vending areas

${ }^{\S} D S D$ Direct seed distribution frequency of use. These SSSA-derived data on the quantities and frequency of seed sharing show that actual farmer-tofarmer seed exchanges may be less widespread than the literature suggests (viz. Jensen et al. 2013; Labeyrie et al. 2014; Pautasso et al. 2013).

\section{Absolute cash expenditures}

Cash transactions, specifically absolute cash expenditures, were further explored here for several reasons. The amount of cash lay out might flag concerns among the more vulnerable - can they afford to buy the seed they need? Also, from a commercial perspective, cash spent is an important signal for those aiming to catalyze seed business development. The phrase 'willingness to pay' is commonly used as a shorthand for examining whether or how much farmers are willing to pay for certified seed (David 2004; Fuglie et al. 2006). As seen above, the concept is too shallow, as farmers do pay for seed, and on a routine basis, and in cash. Hence, the concept might be refined to explore the margins farmers will pay for different qualities of seed. Also, some of this 'willingness' has to be linked to the quantities of seed needed. 'Willingness' for a small amount may have very different financial consequences from willingness for a larger amount.

Table 5 explores specific cash outlays by tallying the full amount of cash payments farmers made in a given season, across the crops, and in the quantities that farmers actually purchased. This type of analysis unfolded in each SSSA, and generally was tracked across two seasons as crop portfolios may shift from one season to another.

Table 5 Average money farmers spent on seed for their three most important crops, in Makueni and Tharaka, Kenya, Long rains, 2011

\begin{tabular}{|c|c|c|c|c|c|c|c|}
\hline \multirow[t]{2}{*}{ Site } & \multirow[t]{2}{*}{ Crop } & \multicolumn{6}{|c|}{ Spending (Kenyan Shillings: KES) ${ }^{\mathrm{a}}$} \\
\hline & & $\mathrm{N}$ growing this crop & Local market & Neighbors & Ag-input shops & all purchases & $\%$ of total \\
\hline \multirow[t]{4}{*}{ Makueni } & maize & 44 & 337.3 & 0.0 & 772.7 & 1110.0 & $57.8 \%$ \\
\hline & cowpea & 43 & 180.6 & 8.3 & 8.1 & 197.1 & $10.3 \%$ \\
\hline & green gram & 42 & 476.2 & 14.3 & 123.8 & 614.3 & $32.0 \%$ \\
\hline & total (of 3) & & 994.1 & 22.6 & 904.7 & 1921.4 & $100.0 \%$ \\
\hline \multirow[t]{4}{*}{ Tharaka } & millets & 44 & 158.0 & 9.5 & 0.0 & 167.5 & $17.1 \%$ \\
\hline & cowpea & 42 & 221.3 & 23.8 & 0.0 & 245.1 & $25.0 \%$ \\
\hline & green gram & 54 & 566.7 & 0.0 & 0.0 & 566.7 & $57.9 \%$ \\
\hline & total (of 3) & & 946.0 & 33.3 & 0.0 & 979.3 & $100.0 \%$ \\
\hline
\end{tabular}

${ }^{\text {a }}$ The approximate exchange rate was $95 \mathrm{KES}$ to 1 US $\$$ during time of survey $(15 \mathrm{Sept}$. 2011), (http://www.xe.com/currencycharts/?from=USD\&to= KES\&view=2Y) though the latter half of 2011 was also a spike period for the KES/ $\$$ rate. Longer-run trend is between 83 and $88 \mathrm{KES} / \$$ 
The example below draws from the SSSA in Kenya and compared cash purchases from two quite distinct sites, both in what was formerly Eastern Province, Kenya. The Makueni site (Kathonwenzi District) exhibits bimodal rainfall at 800 $1200 \mathrm{~mm}$ annually, with maize predominating, along with crops such as cassava, cowpea, and greengrams. The area has a good sized town, Wote (about 56,000), easy access to agro-dealers (generally $<30 \mathrm{~min}$ ) and is only $150 \mathrm{~km}$ from Nairobi and on good macadam roads (i.e., $2 \frac{1}{2} \mathrm{~h}$ travel time). Tharaka Nithi, in contrast, is more of a classic drought-prone zone, bimodal rainfall topping $500-800 \mathrm{~mm}$, with millet and sorghum predominating along with crops such as cowpea and greengram. The area is 2 to $3 \mathrm{~h}$ from Meru town, over poor, largely non-paved roads. Agro-dealer access locally is nearnonexistent although satellite seed sellers sometimes pass on bicycle or motorcycle.

Although the sites are quite different in terms of agroecology and infrastructural development, Table 5 shows that farmers at both sites spent similar amounts on seed accessed through local markets and social networks: 1016.6 and 979.3 KES in Makueni and Tharaka, respectively, about 10-11 \$US. These local market investments were mainly in cowpea and greengram at both sites, as well as maize in Makueni. Such an investment- equivalent to $1 / 2$ small goat (SSSA Kenya) - is striking particularly in drought-prone zones where farmers' incomes are depressed by low harvests and few agroenterprise opportunities.

Additionally, Makeuni farmers made important investments in certified seed for maize and greengram from agroinput shops. Farmers' greengram purchases at the time of the SSSA were for varieties newly put on offer. In contrast, the maize purchases were linked to well-known hybrid varieties even though farmers in the 2011 community assessment had indicated that maize had done poorly for many seasons in a row (since the 2006 harvest) (SSSA Kenya).

Certainly, these are just examples, which need to be multiplied across hundreds of sites and contexts so as to understand farmers' current investments and potential investments in seed types per crop. However, these initial findings suggest that farmers are investing in seed and already at significant levels. Whether local market seed or agro-dealer seed, the scale of expense is formidable from the smallholder perspective.

\section{Who uses specific channels, with focus on local markets}

Local markets emerge as the important seed source overall. This raises questions of whether trends noted above, such as increased market use for legumes or for female-headed households, hold when all factors are considered. In particular, do observed inter-country variations (Table 2 ) reflect national characteristics, or other factors such as crop composition or farm size distribution within each SSSA? Probit regressions explored how country, crop, household characteristics and farm area affect the likelihood of local market use. ${ }^{11}$ The dependent variable was use of local markets to supply seed for a given crop and household ( $n=7436$ in this dataset), with independent variables being countries (6), within-country sites (31), crop clusters (5, as in Table 3), age and gender of household head, family size, and farm area ( 4 categories: $<0.5,0.5$ $1,>1-2$, and $>2$ ha; formula 1 ). As farmers provided quantities obtained from every source used, it was possible to calculate the proportion of seed for a given crop supplied by local markets; in this estimation, local markets were coded as 'used' when they supplied $\geq 25 \%$ of a farmer's seed. ${ }^{12}$ To our knowledge, this is the first large-scale estimation of factors affecting farmers' use of local markets. Table 6 shows the marginal effects of key variables on farmers' use of local markets. ${ }^{13}$

$$
\begin{aligned}
\text { local market }= & \alpha+\beta \text { country } / \text { site }+\delta \text { crop cluster } \\
& +\gamma H H \text { characteristics }+\theta \text { area farmed }+\varepsilon
\end{aligned}
$$

Kenya was used as the referent for country dummies, as its overall local market use was intermediate (Table 2) and agrodealers are relatively well developed. Haitian farmers are significantly more likely to obtain seed from local markets, accounting for other factors, confirming this not a compositional effect (e.g., because the Haiti sample had more legumes than elsewhere), but rather reflects characteristics of Haiti itself. Infrastructure and currency issues noted above help explain why farmers in South Sudan and Zimbabwe are significantly less likely to use local markets. Maize is the referent group for crop clusters; while there is little difference between maize and other cereals, legumes are significantly more likely to be obtained from local markets, vegetative crops less. This supports arguments made elsewhere (Sperling and McGuire 2010) that local market provision is especially important for legumes.

Insights into who uses local markets emerged from household characteristics. Younger farmers used markets more, though the effect is not strong. ${ }^{14}$ The effect of gender of household head was not strong, and varied by country (data not shown). Female-headed households were slightly more likely to use local markets, though only significantly so in DRC $(p<0.10)$, while in South Sudan they were significantly $(p<0.05)$ less likely to use markets. Markets were sparse in

\footnotetext{
${ }^{11}$ This analysis highlights correlations with the factors measured. Gathering detailed household-level data on consumption or income was not the purpose of SSSAs; such data would benefit future models in producing estimations of marginal effects levels.

${ }^{12}$ Other specifications - local market use (any proportion); local market supplies $\geq 50 \%$ of a household's seed for that crop; and $\geq 75 \%$ - produced similar results (coefficient signs, significance levels).

${ }^{13}$ Models also controlled for within-country sites, but these coefficients are not shown.

${ }^{14}$ A 10 year age difference shifts likelihood of local market use by $2.9 \%$.
} 
Table 6 The marginal effects of factors affecting a household's likelihood to obtain $\geq 25 \%$ of their seed of a given crop from local markets (standard errors in parentheses); Kenya is referent group for country dummies, and maize for crop dummies

\begin{tabular}{lc}
\hline Factor & Marginal effect \\
\hline Country & \\
$\quad$ Malawi & $0.00525(0.0343)$ \\
DRC & $0.0382(0.0364)$ \\
Haiti & $0.294(0.0312)^{* * *}$ \\
S Sudan & $-0.185(0.0275)^{* * *}$ \\
Zimbabwe & $-0.363(0.0662)^{* * *}$ \\
Crop & \\
Other cereals & $-0.0235(0.0169)$ \\
Vegetative crops & $-0.399(0.0188)^{* * *}$ \\
Legumes & $0.135(0.0130)^{* * *}$ \\
Other crops & $-0.0920(0.0270)^{* *}$ \\
Age & $-0.00286(0.000403)^{* * *}$ \\
Male-headed & $0.0116(0.0121)$ \\
HH size $\S$ & $0.00185(0.00215)$ \\
Farm area $\S$ & $-0.00633(0.00921)$ \\
Observations & 6873 \\
Pseudo R-squared & 0.1927 \\
\hline
\end{tabular}

Significance: $* p<0.10 ; * * p<0.05, * * * p<0.01$

$\S$ : Household and farm size data not available for Haiti or Zimbabwe, so coefficients here derived from regression models excluding those countries (3583 observations, pseudo R-squared of 0.12)

2010 in South Sudan, with minimal transport infrastructure, so it is perhaps unsurprising that women there were less likely to make long journeys to obtain seed. Finally, cultivated land was used to differentiate wealth categories among smallholders. ${ }^{15}$ In all individual country regressions, the tendency is for greater market use for smaller farms, though this is only significant (at $\mathrm{p}<0.10)$ in DRC. These data suggest that local markets may be particularly important for relatively vulnerable farmers (poorer, or female-headed households).

Table 7 shows \% of seed from the DRC assessment in relation to farm area as a clear illustration of this wider trend. Those with smaller farms access over $1 / 2$ their seed from local markets (across crops) versus less than $1 / 5$ for those in the largest land category. Some parallel trends were noted in the SSSA for Kenya and from a number of other studies that contained more extensive socio-economic background information. In one Rwandan study from the early 1990s, the poorer segments bought $90 \%$ of their bean seed from local markets for the main growing season, compared to $6 \%$ for the relatively rich (CIAT 1991; in Sperling and McGuire 2010).

\footnotetext{
$\overline{15}$ Note that most of the farmers in the SSSA samples would be considered smallholders, though communities regard the different farm size categories used as indicative of important differences in household wellbeing and vulnerability.
}

Table 7 Use of own stock vs. local market according to farm size in eastern DRC, as \% of total seed used by that group of farms

\begin{tabular}{llllll}
\hline Seed source & \multicolumn{2}{l}{ Area cultivated (\%) } & \multirow{2}{*}{ All farms } \\
\cline { 2 - 5 } & $<0.5$ ha & $0.5-1$ ha & $>1-2$ ha & $>2$ ha & \\
\hline Own stock & 17.8 & 24.1 & 33.3 & 77.3 & 35.0 \\
Local market & 54.1 & 51.9 & 49.1 & 17.6 & 44.6 \\
N cases & 174 & 250 & 93 & 27 & 544 \\
\hline
\end{tabular}

Other quantitative studies report comparable conclusions: in Malawi, Uganda, Ethiopia, Burundi, Ethiopia- the very poor are tied relatively more to local markets for seed of select crops than their wealthier neighbors (David and Sperling 1999; McGuire 2008; Sperling 1994). Future research will explore further the relationships between wealth (and farm area) and seed source use.

\section{How farmers accessed new varieties}

As a final theme, the issue of new varieties is addressed. Within the context of strengthening seed systems and fostering seed security, variety introductions can be a relatively economical way to increase production quickly.

Overall, across sites, over a third of farmers, $36 \%$ had accessed some new variety within the previous 5 years (although whether these are 'modern varieties' or new local varieties could not be determined based on variety name alone; Table 8). While the figure appears promising, the findings need to be interpreted in the context of site choice as general SSSA zones were ones of government or NGO intervention. This potential assistance bias might be seen particularly in South Sudan, where about half of sample had received a new variety but where, at the time of the SSSA, the formalsector research system was only just starting to be re-vitalized after a prolonged civil war, and variety releases were very few. The relatively low figure of $14.2 \%$ in Haiti is particularly striking, as that SSSA had the largest (983) and most geographically-spread sample, spanning the country and agro-ecological zones, and was hosted by seven organizations, all with developmental programs. Besides the SSSA country, the only other factor affecting a household's likelihood of accessing a new variety is gender. Male-headed households are slightly (but significantly) more likely to access new varieties (Table 9). ${ }^{16}$

New varieties can potentially be accessed through multiple channels. However, outlets providing the new materials within the SSSA sample were weighted towards government and $\mathrm{NGO} / \mathrm{UN}$ channels, which delivered $2 / 3$ of the varieties,

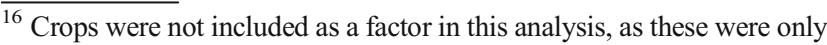
specified for households accessing a new variety.
} 
Table 8 Farmers who obtained a new variety in the previous 5 years and the sources of provision

\begin{tabular}{|c|c|c|c|c|c|c|c|}
\hline \multirow[t]{2}{*}{ Source of new variety } & \multicolumn{5}{|c|}{ SSSA Country (\%) } & \multicolumn{2}{|c|}{ All sites } \\
\hline & Malawi & Kenya & $\mathrm{DRC}$ & Haiti & S Sudan & $\%$ & $\mathrm{~N}$ \\
\hline Friends, neighbors, relatives & 2.2 & 9.3 & 9.5 & 3.2 & 9.7 & 7.7 & 129 \\
\hline Local market & 7.6 & 15.6 & 9.5 & 2.4 & 19.7 & 14.3 & 239 \\
\hline Agro-dealer & 27.1 & 17.8 & 0.0 & 2.8 & 0.8 & 6.9 & 115 \\
\hline CBSG & 0.4 & 0.4 & 3.4 & 6.5 & 0.8 & 1.7 & 29 \\
\hline Government & 50.7 & 39.6 & 0.0 & 10.1 & 5.4 & 16.4 & 275 \\
\hline $\mathrm{NGO} / \mathrm{FAO}$ & 11.1 & 14.2 & 77.6 & 73.3 & 62.9 & 52.0 & 871 \\
\hline Contract seed growers & 0.0 & 1.3 & 0.0 & 0.0 & 0.0 & 0.2 & 3 \\
\hline Other & 0.9 & 1.8 & 0.0 & 1.6 & 0.6 & 0.9 & 15 \\
\hline ALL Sources & 100.0 & 100.0 & 100.0 & 100.0 & 100.0 & 100.0 & 1676 \\
\hline TOTAL new varieties & 225 & 225 & 116 & 247 & 863 & & 1676 \\
\hline Households receiving new variety $-\mathrm{N}$ & 127 & 138 & 44 & 140 & 438 & & 887 \\
\hline No. Households in sample & 180 & 198 & 209 & 983 & 857 & & $2427^{\S}$ \\
\hline Households receiving new variety $-\%$ of sample & $70.6 \%$ & $70.8 \%$ & $22.9 \%$ & $14.2 \%$ & $51.1 \%$ & $36.5 \%$ & \\
\hline
\end{tabular}

$\S$ Dataset on new varieties does not include Zimbabwe sample

largely via free distribution. Local markets served as the major sustainable source, but their performance has been highly variable across countries (with limited presence as a source of innovation in Haiti or Malawi). In terms of crop profiles, maize comprised $31 \%$ of all the 1676 new variety cases. A further $18 \%$ were for sorghum, and $7 \%$ each for groundnut and common bean.

Across sites, agro-dealers provided $6.8 \%$ of the new varieties (compared with $7.5 \%$ of new acquisitions from social networks). Agro-dealers as a source of novel material had an important presence only in Malawi and Kenya, where maize accounted for 79 and $74 \%$ of the new varieties accessed from these outlets. ${ }^{17}$ Note that the site choice among SSSAs spanned very different commercial sector contexts: dealer networks were comparatively well developed in Kenya and Malawi; in contrast, South Sudan and eastern DRC had virtually none.

As a seed source, community-based groups have a very minor importance in providing new varieties (1.7 \% of cases). For supplying volumes of seed, they figure barely at all $(0.5 \%$ of what farmers sow; Table 2). Their relative invisibility comes in spite of the sites generally being ones of NGO intervention and of CBSG's being promoted with regularity, especially by NGOs and the UN system. The relatively higher figure of $6.4 \%$ of new accessions in Haiti from CBSGs might be misleading, as it is a proportion of cases where households did access new varieties, and represents only 16 instances, countrywide (Haiti SSSA).

In sum, delivery channels for new varieties were poorly developed across assessment sites. Farmers could only access

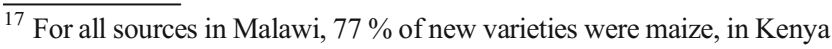
it was $29 \%$.
}

new varieties of most crops through one-off aid provision, usually from NGOs or governments (the latter especially distributing maize). Local markets provided some innovation but were linked to new varieties in an ad hoc manner, rather than via a well-established set of processes. Projecting forward, new varieties will not move quickly or at scale until more impactoriented seed systems receive concerted research and development attention. In the public sector at least, there seems to be an investment lacuna between the science of plant breeding, which receives substantial funds, and the science of delivery.

Table 9 The marginal effects of factors affecting a household's likelihood of obtaining a new variety in the past 5 years (Standard errors in parentheses; $* * p<0.05, * * * p<0.01$ )

\begin{tabular}{lc} 
Marginal effect & \\
\hline Country & \\
$\quad$ Malawi & $0.222(0.0780)^{* * *}$ \\
DRC & $-0.479(0.0586)^{* * *}$ \\
Haiti $\S$ & $-0.570(0.0576)^{* * *}$ \\
S Sudan & $-0.425(0.0614)^{* * *}$ \\
Age & $0.0000472(0.00102)$ \\
Male-headed & $0.0688(0.0278)^{* *}$ \\
HH size & $0.00249(0.00348)$ \\
Farm area & $0.0147(0.0151)$ \\
Observations & 1255 \\
Pseudo R-squared & 0.1594 \\
\hline
\end{tabular}

$\S$ : Household size and farm area data not available for Haiti; this coefficient derived from specification without those factors. New variety access data unavailable for Zimbabwe 


\section{Discussion: investment policy and practice}

The work presented herein results from a large seed system data set, spanning many crops. Overall, smallholder farmers accessed $90.2 \%$ of seed they sowed from informal systems, ${ }^{18}$ with $50.9 \%$ from local markets. In contrast, formal sector sources were modest, even though several decades of investment have largely focused on either the formal public or formal private sector (e.g., Hoegenmeyer n.d.).

To review select findings tied to current models: a) the channels routinely supported supply an insignificant proportion of seed sown by smallholder farmers; $b$ ) new varieties are not being accessed sustainably through supported channels; and c) the array of crops needed for production, nutrition and resilience goals will not likely be promoted via a commercialized formal sector approach alone. Simply, profit margins for self-pollinated crops remain modest as once farmers obtain the novel germplasm, they can re-sow their own seed (Rubyogo et al. 2010). Also, for the vegetatively-propagated crops, few viable commercial options have been identified beyond some initial successes with Irish potato (Sperling et al. 2014).

At a minimum, our results suggest a need to address the imbalance in seed channel focus so as to give attention to the main seed systems smallholders use, including several informal channels. There is also a case for broadening strategy within the formal seed sector to enhance its scope for impact. To spur more gains, it may be opportune to move programmatically toward more integrated seed system approaches that leverage the relative strengths of informal and formal sectors. A range of indicative actions is sketched below for promoting greater formal and informal seed system integration and effectiveness. Most have had a trial phase in the past 5 years and a few have had important expansion.

\section{Promoting more smallholder-responsive /integrated seed systems: entry points from the formal sector}

There are multiple entry points being tested to help make formal seed systems more responsive to smallholder farmer needs. These efforts go beyond scaling up'more of the same' and rather move toward re-designing some of the core parameters which affect the access of a range of clients to the formal sector. Several examples are cited below.

\section{Proximity of agro-dealer providers}

Even for their designated crops (maize and horticultural crops), formal sector outlets rarely can cover the full zones

\footnotetext{
$\overline{18}$ To get $90.2 \%$ for informal, we subtracted from the total any source that could have been formal: agro-dealers, government and $\mathrm{NGO} / \mathrm{UN}$ and contract growers. Table 2 totaled these sources at $9.8 \%$.
}

of farmer need: for example, only $23 \%$ of farmers in Nzaui Kenya were within 1 hour walk of a formal agro-dealer outlet (Farrow et al. 2010). Seed enterprises may be reluctant to serve remote areas. Noted by one set of observers "For commercial seed enterprises a key constraint is their so called zone of mobility and most indicate that their produce can be sold within a $200 \mathrm{~km}$. radius..." (USAID 2013).

\section{Licensing of non-seed outlets}

Experience shows that outlets can be scaled out through building on existing non-seed networks. Key to scaling is quickly to leverage conduits that a) require no new infrastructural development; and b) have proven durable themselves, prior to adding the dimension of seed sales and information. Good experiences have been achieved through several 'value addition' strategies. Seed sale has been added to rural 'Mom and Pop' stores which sell basic staples in both Zimbabwe (through the CARE Agent Program; Zimbabwe SSSA and NRI 2003) and Timor-Leste (through a Mercy Corps initiative; TL SSSA). Seed sale also routinely takes place in supermarkets of Malawi. Colored green or pink maize seed, along with clear variety labels, signals that seed is being sold. Horticultural seed is also on sale, and, inadvertently, bean seed, as the one-kilo packs bagged for consumption are sometimes bought for planting (Malawi SSSA). Within the supermarket model, there should be room to expand at least the range of legume seed on offer. ${ }^{19}$

\section{Packet size}

Formal sector companies generally prefer to sell larger pack sizes: typically $2-5 \mathrm{~kg}$ bags for legumes or $10,20,50 \mathrm{~kg}$ bag sizes for the predominant crop, maize. Companies assume farmers prefer to buy seed to cover their full holdings. In contrast, research suggests that smallholder farmers often buy high quality seed mainly to obtain new variety material (Rohrbach and Malusalila 1999). Recent experimental programs have facilitated delivery and sale of smaller seed pack sizes which farmers find more affordable. In 2012 alone, a single project, Tropical Legumes II, sold 943,170 small seed packs (100 g, $250 \mathrm{~g}$ and upwards) of six legume crops in 13 African countries (Sperling and Boettiger 2013). Some private sector companies are moving to this model, at scale, e.g., Drylands in eastern Kenya packed 50MT of beans in small packs in 2013 (Sperling et al. 2014) and AGRA now also trains its private sector grantees to pack seed in smaller units (Sperling and Boettiger 2013). Smallholders already spend money for seed (Tables 4 and 5); smaller packs can encourage smallholders to try new varieties, and expand companies' client-base.

\footnotetext{
${ }^{19}$ National seed laws will affect the scope for expansion.
} 
Promoting more smallholder-responsive/integrated seed systems: entry points from the informal sector

The informal sector handles the wider profile of crops sowed by smallholder farmers (with some notable exceptions of hybrid and modern open pollinated variety (OPV) maize and hybrid vegetable seed). There are multiple entry points for strengthening this sector: a) helping farmers to improve the quality of their own saved seed; b) improving the quality of seed on offer in local seed/grain markets; and c) strengthening marketing and information systems.

\section{Seed storage methods}

Investing in good seed storage, that is helping farmers save their seed 'at the front end' (preventatively), should be seen as a strategic investment (Walsh et al. 2014). Particularly with vulnerable farmers and in high stress regions, better seed storage options may mean less need for emergency assistance when times get tough, for example, when drought or flood or other stresses require multiple sowings. Advantages for farmers in storing their own seed include: cash outlays are reduced, seed is available on time and just nearby, and varieties and management requirements (including modern varieties they have stored) are familiar to them (Walsh et al. 2014). Unfortunately, farmers often struggle to prevent storage losses, especially with maize and legumes, with losses routinely reaching $30 \%$ upwards (e.g., Meikle et al. 2002). Some new storage technologies proving effective include hermetic storage bags (Mutungi et al. 2014) and small metal silos (TL SSSA). Research homing in on the cost-benefits of different storage materials and sizes might sharpen technologies further (Jones and Walsh 2014).

\section{Local seed market enhancement ('potential seed')}

To date, little developmental attention has been focused local seed markets. This gap is partly due to a reluctance by formal sector actors to consider goods from such channels as representing potential seed at all, and their assessing use of market seed as 'risky' (Lipper et al. 2010; Sperling and McGuire 2010). In contrast, farmers in select parts of the world explicitly use the market to defer risk: they sell legumes at harvest and buy back seed at sowing time, so as to transfer the risk of storage losses over to traders (example, Haiti SSSA).

Variety quality and markets Seed/grain traders are generally left out of formal seed sector planning but they could be important partners in moving new varieties. Distribution of variety samples (to stimulate demand); sale of small packets of certified seed in open market venues; and sale of modern varieties in bulk are options that have had some initial successes in parts of east and central Africa (McGuire and Sperling 2008). The volumes moved by traders and their geographic scope of action make them interesting candidates for broadening access to new varieties among smallholders, even in more isolated regions. Conditioning and storage issues would need to be addressed if stock turnover is slow and any certified seed sale via trader networks would need to be aligned with country-specific seed law regulations (Sperling et al. 2014).

Seed quality and markets Seed/grain traders could also be partners in improving the seed quality per se. Large traders (e.g., moving 50-200 MT/season in the SSSAs monitored) have been known to respond to quality innovations if new business opportunities arise. For example, in order to participate in CARE's seed relief program in eastern Ethiopia in 2002, traders adopted several seed quality enhancing practices: improving warehouse conditions, maintaining specific seed stores, separating out specific varieties (McGuire and Sperling 2008). The same phenomenon of heightening quality has been observed with food procurement. Traders working with the World Food Program's Purchase 4 Progress Program (P4P) made investments in quality assurance equipment which purportedly led to better quality of food products found in local markets http://www.wfp.org/purchase-progress/news/ blog/new-study-reveals-wfp $\% \mathrm{E} 2 \% 80 \% 99$ s-impact-africanfood-markets.

\section{Marketing information systems for informal/integrated sector}

Seed-related information systems need to be vastly improved to capture the potential of an evolving, more integrated seed sector (see also Audi et al. 2010). Traders might be one important channel to engage more fully. Examples of types of information traders might provide farmers could include, inter alia: a) existence of new varieties and their traits; b) location of potential supplies; c) information from others who have tested the materials. Equipping traders with up-to-date seedrelated information would raise awareness quickly among smallholder clients, but also among other trader suppliers serving remote communities. As with the case of small packs, engaging large traders as information conduits could facilitate important scaling benefits.

Farmers themselves could increasingly access this focused information directly, were it readily available. Even in Africa, some $86 \%$ of the population currently has access to mobile phones (http://uk.kantar.com/tech/mobile/mobile-phone-usein-africa/), including many who live in rural areas. Current information approaches such as field demonstrations, agricultural shows, posters and technical leaflets tend to describe variety attributes and provide one-way communication with farmers. Minimally, those testing any new varieties, especially in on-farm trials, should be linked systematically to 
two-way, mobile feedback systems (van Etten 2011). Also, experimental initiatives might aim to link mobile phone use with information on seed availability and supplier locations (e.g., Farrow et al. 2011).

The central message of these select examples is that local markets are the main source for smallholder farmer seed yet currently remain outside the scope of explicit and supportive seed sector interventions. Given that seed/grain markets provide not just the bulk of seed in absolute quantities, but are key for accessing a portfolio of crops, including most legumes, such an omission seems shortsighted. Certainly, those with a development vision toward nutrition-sensitive agriculture and more resilient farming systems might analyze the case of local seed/grain strengthening as one of unrealized potential.

\section{Conclusion}

All seed sectors have to be strengthened to deliver the types of products needed to catalyze smallholder advances: to encourage increased production; nutritional gains; and to foster farming system resilience. 'More of the same' seems unwise as the bulk of varieties and absolute quantities of seed are not now being presently accessed through the channels routinely supported by development efforts. As a concomitant message, continued public-sector breeding efforts may not realize their investments if varieties cannot be delivered in more sustainable ways, but also quickly and at scale. Variety use by farmers should be a dynamic process, with additions or substitutions as better options become available.

Overall, the data show that seed sector strategy has to become more smallholder-focused and that sharpened goals have to drive the types of approaches used (Sperling and McGuire 2012). For instance, brute production gains require a distinct strategy from those aiming for system resilience through offering a portfolio of crops and varieties. The data also show that impressive results, at scale, are not necessarily achieved by focusing on the more common metrics used to measure seed sector success. Examples include "tons of seed produced" which is often only a function of how much financial assistance has been allotted or 'value of seed sector', which looks only at the supply side monies earned. To move towards more impact-oriented seed sector development, our metrics might also be broadened especially to put emphasis on the catalytic options which show that seed channels - formal, informal and integrated combinations - are actually working to reach smallholders with the seed products and information that such farmers want and need.

Acknowledgments We acknowledge the support of the United States Agency for International Development/US Office of Foreign Disaster Assistance, for funding the development of the SSSA and the implementation of the case studies, and, in particular, thank Drs. Julie March and
Eric Witte. The work of dedicated field teams in Haiti, Zimbabwe, South Sudan and Kenya, Malawi and the Democratic Republic of Congo is also gratefully noted, as is the assistance of Borja Perez-Viana with statistical analysis. Finally, thanks to the four reviewers who shared detailed and useful comments.

Open Access This article is distributed under the terms of the Creative Commons Attribution 4.0 International License (http:// creativecommons.org/licenses/by/4.0/), which permits unrestricted use, distribution, and reproduction in any medium, provided you give appropriate credit to the original author(s) and the source, provide a link to the Creative Commons license, and indicate if changes were made.

\section{References}

Almekinders, C. J. M., \& Hardon, J. (2000). Towards integrated seed supply. In C. J. M. Almekinders \& W. S. de Boef(Eds.), Encouraging diversity: The conservation and development of plant genetic resources (pp. 249252). London: Intermediate Technology Publications.

Audi, P., Nagarajan, L., Jones, R., \& Ibrahim, M. S. (2010). Pigeonpea seed supply and diversity: A case study of local seed markets in makueni district, eastern Kenya. In L. Lipper, C. L. Anderson, \& T. J. Dalton (Eds.), Seed trade in rural markets: Implications for crop diversity and agricultural development (pp. 95-123). London: Earthscan.

Aw-Hassan, A., Mazid, A., \& Salahieh, H. (2008). The role of informal farmer-to-farmer seed distribution in diffusion of new barley varieties in Syria. Experimental Agriculture, 44, 413-431.

Badstue, L. B. (2006). Smallholder seed practices: Maize seed management in the central valleys of Oaxaca, Mexico. Wageningen: $(\mathrm{PhD})$, Wageningen University.

Bezner Kerr, R. (2013). Seed struggles and food sovereignty in northern Malawi. The Journal of Peasant Studies, 40(5), 867-897.

Bonny, S. (2014). Taking stock of the genetically modified seed sector worldwide: market, stakeholders, and prices. Food Security, 6(4), 525-540.

Bouis, H. E., \& Welch, R. M. (2010). Biofortification - a sustainable agricultural strategy for reducing micronutrient malnutrition in the global south. Crop Science, 50(S1), S20-S32.

Byrne, K. G., March, J., McGuire, S., Meissner, L., \& Sperling, L. (2013). The role of evidence in humanitarian assessment: the seed system security assessment and the emergency market mapping and analysis. Disasters, 37, S83-S104.

Cavatassi, R., Lipper, L., \& Narloch, U. (2011). Modern variety adoption and risk management in drought prone areas: insights from the sorghum farmers of eastern Ethiopia. Agricultural Economics, 42(3), 279-292.

Chisinga, B. (2011). Seeds and subsidies: the poliutical economy of input programmes in Malawi. IDS Bulletin, 42, 59-68.

Christinck, A. (2002). This seed is like ourselves: A case study from rajasthan, india, on the social aspects of biodiversity and farmers' management of pearl millet seed. Weikersheim: Margraf Verlag.

CIAT. (1991). Comparisons of seed quality, from bean seed obtained from range of formal and informal sources annual report bean program, 1991 (pp. 310-312). Cali: CIAT.

David, S. (2004). Farmer seed enterprises: a sustainable approach to seed delivery? Agriculture and Human Values, 21(4), 387-397.

David, S., \& Sperling, L. (1999). Improving technology delivery mechanisms: lessons from bean seed systems research in eastern and central Africa. Agriculture and Human Values, 16(4), 381-388.

De Waal, A. (1991). Emergency food security in western Sudan: What is it for? In S. Maxwell (Ed.), To cure all hunger: Food policy and food security in Sudan (pp. 68-84). London: Intermediate Technology.

Farrow, A., Risinamhodzi, K., Zingore, S., \& Delve, R. J. (2011). Spatially targeting the distribution of agricultural input stockists in Malawi. Agricultural Systems, 104(9), 694-702. 
Farrow, A., Seward, P., \& Ssengooba, P. (2010). Final report and lessons learned from the project: 'Nodes of growth: Improving legume seed networks in Kenya. Kampala: CIAT.

Fuglie, K., Adiyoga, W., Asmunati, R., Mahalaya, S., \& Suherman, R. (2006). Farm demand for quality potato seed in Indonesia. Agricultural Economics, 35(3), 257-266.

Giller, K. E. (2001). Nitrogen fixation in tropical cropping systems. Wallingford: CABI.

GTZ, \& CGN. (2000). Support for the informal seed sector in development cooperation: Conceptual issues (pp. 30): GTZ.

Guei, R. G., Barra, A., \& Drissa, S. (2011). Promoting smallholder seed enterprises: quality seed production of rice, maize, sorghum and millet in northern Cameroon. International Journal of Agricultural Sustainability, 9(1), 91-99.

Hanke, S. H., \& Kwok, A. K. F. (2009). On the measurement of Zimbabwe's hyperinflation. Cato Journal, 29(2), 353-364.

Hoegenmeyer, T. (n.d.). History of the us hybrid corn seed industry, from http://imbgl.cropsci.illinois.edu/school/2014/11 THOMAS HOEGEMEYER.pdf

Jensen, H. R., Belqadi, L., de Santis, P., Sadiki, M., Jarvis, D. I., \& Schoen, D. J. (2013). A case study of seed exchange networks and gene flow for barley (Hordeum vulgare subsp. vulgare) in Morocco. Genetic Resources and Crop Evolution, 60, 1119-1138.

Jones, M., \& Walsh, S. (2014). Seed storage brief \#3: Economics and promotion: Insights for program design. Nairobi: Catholic Relief Services.

Jones, R. B., Audi, P. A., \& Tripp, R. (2001). The role of informal seed systems in disseminating modern varieties. The example of pigeonpea from a semi-arid area of Kenya. Experimental Agriculture, 37(4), 539-548.

Labeyrie, V., Rono, B., \& Leclerc, C. (2014). How social organization shapes crop diversity: an ecological anthropology approach among tharaka farmers of mount Kenya. Agriculture and Human Values, 31, 97-107.

Langyintuo, A., Mwangi, W., Diallo, A. O., MacRobert, J., Dixon, J., \& Bänzinger, M. (2010). Challenges of the maize seed industry in eastern and southern Africa: a compelling case for private-public intervention to promote growth. Food Policy, 35(4), 323-331.

Levy, P. S., \& Lemeshow, S. (2008). Sampling of populations: Methods and applications. Hoboken: Wiley.

Lipper, L., Anderson, L., \& Dalton, T. J. (Eds.). (2010). Seed trade in rural markets: Implications for crop diversity and agricultural development. London: Earthscan.

Louwaars, N., \& de Boef, W. (2012). Integrated seed sector development in Africa: a conceptual framework for creating coherence between practices, programs, and policies. Journal of Crop Improvement, 26, 39-59.

Louwaars, N. P., de Boef, W. S., \& Edeme, J. (2013). Integrated seed sector development in Africa: a basis for seed policy and law. Journal of Crop Improvement, 27(2), 186-214.

Marfo, K. A., Dorward, P. T., Craufurd, P. Q., Ansere-Bioh, F., Haleegoah, J., \& Bam, R. (2008). Identifying seed uptake pathways: the spread of agya amoah rice cultivar in southwestern Ghana. Experimental Agriculture, 44(02), 257-269.

McGuire, S. J. (2008). Securing access to seed: social relations and sorghum seed exchange in eastern Ethiopia. Human Ecology, 36(2), 217-229.

McGuire, S. J., \& Sperling, L. (2008). Leveraging farmers' strategies for coping with stress: seed aid in Ethiopia. Global Environmental Change, 18(4), 679-688

McGuire, S. J., \& Sperling, L. (2011). The links between food security and seed security: facts and fiction that guide response. Development in Practice, 21(4-5), 493-508.

McGuire, S. J., \& Sperling, L. (2013). Making seed systems more resilient to stress. Global Environmental Change, 23, 644-653.

Meikle, W. G., Markham, R. H., Nansen, C., Holst, N., Degbey, P., Azoma, K., \& Korie, S. (2002). Pest management in traditional maize stores in west Africa: a farmer's perspective. Journal of Economic Entomology, 95(5), 1079-1088.
Mutungi, C. M., Affognon, H., Njoroge, A. W., Baributsa, D., \& Murdock, L. L. (2014). Storage of mung bean (Vigna radiata [L.] Wilczek) and pigeonpea grains (Cajanus cajan [1.] Millsp) in hermetic triple-layer bags stops losses caused by Callosobruchus maculatus (f.) (Coleoptera: Bruchidae). Journal of Stored Products Research, 58, 39-47.

Nagarajan, L., Smale, M., \& Glewwe, P. (2007). Determinants of millet diversity at the household-farm and village-community levels in the drylands of India: the role of local seed systems. Agricultural Economics, 36(2), 157-167.

Nordhagen, S., \& Pascual, U. (2013). The impact of climate shocks on seed purchase decisions in Malawi: implications for climate change adaptation. World Development, 43, 238-251.

NRI. (2003). Agribusiness entrepreneur network and development programme (agent), from http://projects.nri.org/nret/SPCDR/Chapter3/ services-3-4-2-2.htm

Odame, H., \& Muange, E. (2011). Can agro-dealers deliver the green revolution in Kenya? IDS Bulletin, 42(4), 78-89.

Pautasso, M., Aistara, G., Barnaud, A., Caillon, S., Clouvel, P., Coomes, O. T., Delêtre, M., Demeulenaere, E., De Santis, P., Doring, T., Eloy, L., Emperaire, L., Garine, E., Goldringer, I., Jarvis, D., Joly, H. I., Leclerc, C., Louafi, S., Martin, P., Massol, F., McGuire, S., McKey, D., Padoch, C., Soler, C., Thomas, M., \& Tramontini, S. (2013). Seed exchange networks for agrobiodiversity conservation. A review. Agronomy for Sustainable Development, 33(1), 151-175.

Rajalahti, R. (2013). The World Bank support to seed sector development, may 2, 2013. Washington: Paper presented at the Supporting Comprehensive Seed Sector Development.

Remington, T., Maroko, J., Walsh, S., Omanga, P., \& Charles, E. (2002). Getting off the seeds-and-tools treadmill with crs seed vouchers and fairs. Disasters, 26(4), 316-328.

Rohrbach, D. D., \& Malusalila, P. (1999). Developing rural retail trade of seed through small packs. Paper presented at the Conference 'Linking Seed Producers and Consumers: Diagnosing constraints in institutional performance - Zimbabwe', ICRISAT and ODI, Bulawayo.

Rubyogo, J. C., Sperling, L., Muthoni, R., \& Buruchara, R. (2010). Bean seed delivery for small farmers in sub-saharan Africa: the power of partnerships. Society and Natural Resources, 23(4), 285-302.

Shi, W., \& Tao, F. (2014). Vulnerability of African maize yield to climate change and variability during 1961-2010. Food Security, 6(4), 471481.

Smale, M., Byerlee, D., \& Jayne, T. S. (2011). Maize revolutions in subSaharan Africa (p. 34). Washington: World Bank, Policy Research Working Paper 5659.

SourceWatch. (2012). Agra's programme for africa's seeds systems Retrieved 12 March 2015, from http:/www.sourcewatch.org/ index.php/AGRA\%27s_Programme for_Africa $\% 27$ s_Seeds Systems

Sperling, L. (1994). Summary report. Analysis of bean seed channels in the Great Lakes region: South Kivu, Zaire, southern Rwanda, and select bean-growing zones of Burundi (p. 13). Rwanda: CIAT/ RESAPAC.

Sperling, L. (2008). When disaster strikes: A guide for assessing seed security. Cali: CIAT.

Sperling, L., \& Boettiger, S. (2013). Impacts of selling seed in small packs: Evidence from legume sales: AgPartnerXChange.

Sperling, L., Boettiger, S., \& Barker, I. (2014). Integrating seed systems Planning for Scale Brief \# 3: AgPartnerXChange.

Sperling, L., \& Cooper, D. (2004). Understanding seed systems and strengthening seed security: A background paper. In L. Sperling, T. Osborn, \& D. Cooper (Eds.), Towards effective and sustainable seed relief activities (pp. 7-33). Rome: FAO. Plant Production and Protection Paper 181. 
Sperling, L., \& McGuire, S. (2010). Understanding and strengthening informal seed markets. Experimental Agriculture, 46(2), 119-136.

Sperling, L., \& McGuire, S. J. (2012). Fatal gaps in seed security strategy. Food Security, 4(4), 569-579.

USAID. (2013). Seedclir Tanzania pilor report enabling agricultural trade. Washington: USAID.

van Etten, J. (2011). Crowdsourcing crop improvement in sub-saharan africa: a proposal for a scalable and inclusive approach to food security. IDS Bulletin, 42(4), 102-110.

Walsh, S., Baributsa, D., Remington, T., \& Sperling, L. (2014). Seed storage brief \#2: Hermetic seed storage technology: Principles, use, and economics - a practitioner's guide. Nairobi: Catholic Relief Services.

\section{Seed System Security Assessments - core data set}

\section{Northern Katanga, Democratic Republic of Congo 2012}

CIAT, UEA/Dev, CRS, and Caritas, 2012. Seed System Security Assessment, northern Katanga (Kalemie and Nyunzu Territories) Democratic Republic of Congo. Sept 2012. Kinshasa: Catholic Relief Services and International Center for Tropical Agriculture http://seedsystem.org/wp-content/uploads/2013/07/SSSA-finalreport-northern-Katanga.pdf

\section{Southern Malawi 2011}

CIAT, WALA, CRS and Government of Malawi. Seed System Security Assessment, Southern Malawi. October 2011. Blantyre, Malawi: CRS and International Center for Tropical Agriculture. http:// seedsystem.org/wp-content/uploads/2013/07/SSSA-SouthernMalawi-Final-Report-.pdf

\section{Eastern and Coastal Kenya 2011}

CIAT, CRS, Caritas, KARI, World Vision and University of East Anglia. Seed System Security Assessment, Eastern and Coastal Kenya. September 2011. Nairobi, Kenya: Catholic Relief Services and International Center for Tropical Agriculture. http://seedsystem. org/wp-content/uploads/2013/07/eastern_coastal_kenya_final_ report.pdf

\section{South Sudan 2010}

CIAT, FAO, MAF-GoSS, AAH-I, ACTED, ADRA, AMURT, CRS, DRC, NPA, 2011. Seed System Security Assessment, Southern Sudan, November-December 2010. Funded by the European Commission Humanitarian Aid Department and the Office of Foreign Disaster Assistance, United States Agency for International Development. Juba, Southern Sudan: FAO and CIAT. http://seedsystem.org/wp-content/uploads/2013/07/sssa_southern_ sudan.pdf

\section{Haiti 2010}

CIAT, CRS, SNS-MARDNR, UEA, FAO, World Concern, Save the Children, ACDI/VOCA, Save the Children and World Vision, 2010. Seed System Security Assessment, Haiti. A study funded by the United States Agency for International Development, Office of Foreign Disaster Assistance. (USAID/ODFA) August 2010. Arusha, Tanzania: International Center for Tropical Agriculture. http:// seedsystem.org/wp-content/uploads/2013/07/SSSA-Haiti-MainReport.pdf

\section{Zimbabwe 2009}

CIAT, CRS, World Vision, Care, AGRITEX and CIMMYT, 2009. Seed System Security Assessment, Zimbabwe. A study funded by the United States Agency for International Development. Office of Foreign Disaster Assistance. in July 2009 Rome: International Center for Tropical Agriculture. http://seedsystem.org/wp-content/ uploads/2013/07/zimbabwe_2009_final_report.pdf

Also cited

Timor-Leste 2013

CRS, Mercy Corps, MAF/Seeds of Life, CARE, CIAT and UEA/Dev. Seed System Security Assessment, Timor-Leste October 2013. Dili: Timor-Leste http://seedsystem.org/wp-content/uploads/2014/05/ SSSA-Timor-Leste-report-final.pdf

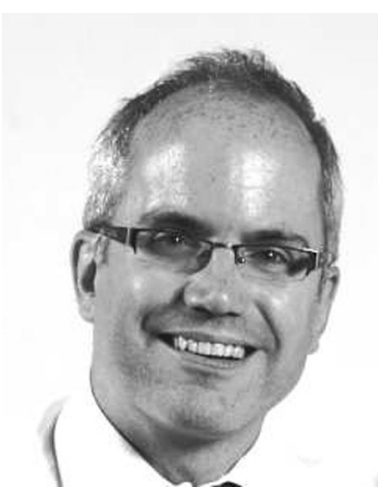

Shawn McGuire is a Senior Lecturer in Natural Resources, in the School of International Development, University of East Anglia (Norwich, UK). His research on smallholder farmers' use of seed systems seeks to promote better policy and practice around technology transfer and food security, across a number of developing countries. Much of this work, in collaboration with Sperling, is gathered in the website www. seedsystem.org. Other research interests include understanding the challenges facing innovation systems in developing countries as they build capacity in agricultural biotechnology (molecular breeding), and the political debates surrounding genetic resource management. He has authored over 25 articles or book chapters: besides those cited above, recent ones include: "Farmer seed networks make a limited contribution to agriculture? Four common misconceptions." (Coomes et al., Food Policy), and "Measuring effectiveness, efficiency and equity in an experimental Payments for Ecosystem Services trial.” (Martin et al., Global Environmental Change). 


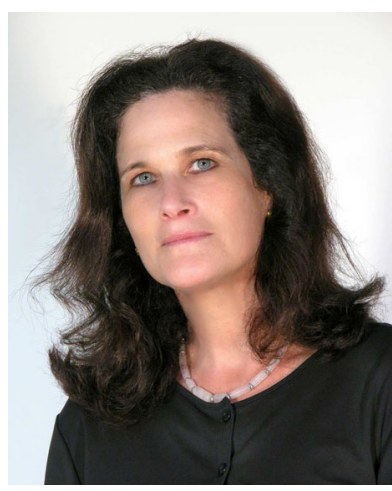

Louise Sperling is a Senior Technical Advisor on Seed Systems for Catholic Relief Services (CRS), and previously a Principal Researcher-Consultant at the International Center for Tropical Agriculture (CIAT). She cofounded www.seedsystem.org as a resource for practice, research and policy, and has managed and technically backstopped projects and programs in over 25 countries of Africa, Asia and Latin America. Her focus is on impact-oriented plant breeding, seed systems, and delivery approaches - with all programs centering around gender equity and farmer empowerment. Sperling's work embraces, 'normal' small farmer and pastoral systems as well as high stress ones: for instance she led research missions linked to: the 198385 seminal drought across East Africa, the 1994 civil war and genocide in Rwanda, the 2010 earthquake in Haiti, and the 2011 Referendum in South Sudan. Widely consulting for a range of agencies (the UN system, the World Bank, Rockefeller, northern and southern NGOs), Sperling is the author of over seventy articles and book chapters, including, recent pieces: Making seed systems more resilient to stress (Global Environmental Change, 2013, McGuire and Sperling); Persistent myths about emergency seed aid (Food Policy 2010, Sperling and McGuire); and Bean seed delivery in sub-Saharan Africa: the power of partnerships Society and Natural Resources, 2010, Rubyogo, Sperling, Muthoni and Buruchara). 